\title{
Staphylococcal Proteases Aid in Evasion of the Human Complement System
}

\author{
Monika Jusko ${ }^{a}$ Jan Potempa ${ }^{b, c}$ Tomasz Kantyka ${ }^{b}$ Ewa Bielecka ${ }^{b}$ \\ Halie K. Miller ${ }^{d}$ Magdalena Kalinska $^{b}$ Grzegorz Dubin ${ }^{b}$ Peter Garred ${ }^{\mathrm{e}}$ \\ Lindsey N. Shaw ${ }^{d}$ Anna M. Blom ${ }^{a}$ \\ ${ }^{a}$ Section of Medical Protein Chemistry, Department of Laboratory Medicine, Skåne University Hospital, Lund \\ University, Malmö, Sweden; ${ }^{b}$ Department of Microbiology, Faculty of Biochemistry, Biophysics and Biotechnology, \\ Jagiellonian University, Krakow, Poland; ' Center for Oral Health and Systemic Diseases, University of Louisville \\ School of Dentistry, Louisville, Ky., and d Department of Cell Biology, Microbiology and Molecular Biology, University \\ of South Florida, Tampa, Fla., USA; ${ }^{e}$ Laboratory of Molecular Medicine, Department of Clinical Immunology, \\ Rigshospitalet, University of Copenhagen, Copenhagen, Denmark
}

\section{Key Words}

Complement · Immune evasion · Proteases $\cdot$ Staphylococcus aureus - Virulence factors

\begin{abstract}
Staphylococcus aureus is an opportunistic pathogen that presents severe health care concerns due to the prevalence of multiple antibiotic-resistant strains. New treatment strategies are urgently needed, which requires an understanding of disease causation mechanisms. Complement is one of the first lines of defense against bacterial pathogens, and S. aureus expresses several specific complement inhibitors. The effect of extracellular proteases from this bacterium on complement, however, has been the subject of limited investigation, except for a recent report regarding cleavage of the $\mathrm{C} 3$ component by aureolysin (Aur). We demonstrate here that four major extracellular proteases of $S$. aureus are potent complement inhibitors. Incubation of human serum with the cysteine proteases staphopain A and staphopain B, the serine protease $\mathrm{V} 8$ and the metalloproteinase Aur resulted in a drastic decrease in the hemolytic activity of serum, whereas two staphylococcal serine proteases $\mathrm{D}$ and $\mathrm{E}$, had no effect. These four proteases were found to inhibit all pathways
\end{abstract}

of complement due to the efficient degradation of several crucial components. Furthermore, S. aureus mutants lacking proteolytic enzymes were found to be more efficiently killed in human blood. Taken together, the major proteases of $S$. aureus appear to be important for pathogen-mediated evasion of the human complement system.

ㄷ) 2013 S. Karger AG, Basel

\section{Introduction}

Staphylococcus aureus has long been recognized as one of the most threatening opportunistic pathogens. About $20 \%$ of the human population are persistent carriers of $S$. aureus, and another $60 \%$ are colonized intermittently [1]. The bacterium can remain within the host in a commensal state, but can also cause a wide spectrum of clinical manifestations, ranging from skin-limited abscesses and wound infections, to life-threatening diseases, including pneumonia, bacteremia, sepsis, endocarditis or toxic shock syndrome [2]. It has also become a major public health threat due to the increased prevalence of multiple antibiotic-resistant strains, such as methicillin-resistant S. aureus. The emergence of vancomycin-resistant strains

\section{KARGER}

E-Mail karger@karger.com

www.karger.com/jin (c) 2013 S. Karger AG, Basel

$1662-811 \mathrm{X} / 13 / 0061-0031 \$ 38.00 / 0$
Prof. Anna M. Blom

The Wallenberg Laboratory, Department of Laboratory Medicine

Lund University, Inga Marie Nilsson Street 53, Floor 4

SE-20502 Malmö (Sweden)

E-Mail Anna.Blom@med.lu.se 
brings back the terrifying spectre of fatal bloodstream infections from the pre-antibiotic era, and emphasizes the need for the development of new treatment strategies, for which a deep comprehension of the pathogenic mechanisms of $S$. aureus is necessary. In terms of human virulence, $S$. aureus is perhaps the most successful bacterium, as it produces a large arsenal of tightly regulated virulence factors that can be exploited in different host environments [3]. It is clear that complement system evasion by $S$. aureus is an important challenge in the establishment of a successful infection, since the repertoire of staphylococcal molecules targeting this system is extensive. Even though, as a Gram-positive bacterium with a thick layer of peptidoglycan, this pathogen is insensitive to complement-mediated lysis, the three activation pathways of complement ensure that $S$. aureus is quickly recognized and opsonized for efficient phagocytosis. The classical pathway is triggered when the $\mathrm{C} 1$ complex binds to invading pathogens, either directly or via immunoglobulins, whereas the lectin pathway is able to recognize microbial polysaccharides via collectins such as mannosebinding lectin (MBL) or ficolins. Finally, complement can also be activated and amplified through the alternative pathway, which is not so much an activation pathway, but rather a failure to appropriately regulate the constant, low-level spontaneous activation of C3. All three pathways lead to opsonization of the pathogen with $\mathrm{C} 3 \mathrm{~b}$ and fragments thereof. Furthermore, anaphylatoxins $\mathrm{C} 5 \mathrm{a}$ and $\mathrm{C} 3 \mathrm{a}$ are released to activate and attract phagocytes to the site of infection. The end result of the complement cascade is the formation of the membrane attack complex and bacterial cell lysis in the case of Gram-negative bacteria. The host manages to protect itself from bystander damage following complement activation through the expression of complement inhibitors. Unfortunately for the host, versatile strategies of complement evasion have been developed by bacteria [4]. S. aureus expresses numerous molecules, both secreted and surface bound, targeting all stages of complement [5]. Their functions range from binding immunoglobulins and acquiring host complement regulators, via inhibition of $\mathrm{C} 3 / \mathrm{C} 5$ conversion, to attenuating complement effector mechanisms, e.g. chemotaxis. In addition, $S$. aureus also secretes several proteases that may provide the bacterium with additional complement resistance in a manner akin to that observed for the periodontal pathogens Porphyromonas gingivalis, Prevotella intermedia and Tannerella forsythia [6-8]. S. aureus secretes several major proteases, including two cysteine proteases (staphopain A, ScpA, and staphopain $\mathrm{B}, \mathrm{SspB}$ ), a serine protease (V8 or SspA), and a metallo- proteinase (aureolysin, Aur) [9]. The role of these enzymes in pathogenicity has been well documented [10]. For example, S.-aureus-derived proteases are able to inactivate $\alpha_{1}$-protease inhibitor and $\alpha_{1}$-antichymotrypsin, endogenous protease inhibitors essential for controlling neutrophil serine proteases $[11,12]$. The cysteine proteases of $S$. aureus degrade elastin, fibrinogen and collagen, potentially leading to tissue destruction and ulceration $[13,14]$, while SspB affects the interaction of neutrophils and monocytes with macrophages [15]. Additionally, V8 degrades human immunoglobulins [16], whilst Aur contributes to staphylococcal immune evasion by cleavage of LL-37 [17]. Furthermore, the action of Aur on complement component $\mathrm{C} 3$ was recently characterized in detail, showing that Aur cleaves $\mathrm{C} 3$ to $\mathrm{C} 3 \mathrm{~b}$ at a site only two amino acids different from that targeted by the complement C 3 convertases. Additionally, it was shown that this $\mathrm{C} 3 \mathrm{~b}$ is then rapidly degraded by factor $\mathrm{H}$ and factor I present in serum [18]. As a result, bacteria are poorly opsonized with $\mathrm{C} 3 \mathrm{~b}$, and this attenuates phagocytosis and killing by neutrophils [18]. These activities of Aur were related to its proteolytic activity, and a major effect on degradation of C3 was lost in an Aur-deficient strain [18]. In addition, Aur activates prothrombin [19], and the staphopains and V8 act on kininogen [20, 21], thereby suggesting a possible role of these proteases in septic staphylococcal infections. In the current study, we investigated the impact of the major staphylococcal proteases in complement evasion.

\section{Materials and Methods}

\section{Ethics Statement}

The ethics board of Lund University has approved the blood collection from healthy volunteers.

\section{Sera}

Normal human serum (NHS) was obtained from 10 healthy volunteers, pooled and stored at $-80^{\circ} \mathrm{C}$. Serum deficient in $\mathrm{C} 1 \mathrm{q}$ was obtained from Quidel.

\section{Proteins}

S. aureus cysteine proteases ScpA and SspB were purified from strain V8-BC10 or 8325-4 culture supernatants using a modification of a method described previously $[14,22]$. The $S$. aureus serine protease V8 (glutamyl-endopeptidase) and the metalloproteinase Aur were purified from culture medium of strain V8-BC10 as described [23]. S. aureus serine proteases D (SplD) and E (SplE) were expressed recombinantly in Escherichia coli BL21 (DE3; Invitrogen) and purified as described [24]. The purity of proteins was evaluated by SDS-PAGE and their activity was confirmed using specific substrates. The activity of ScpA and SspB was determined by active site titration with E-64 [L-trans-epoxysuccinyl-leucylam-
32

Innate Immun 2014;6:31-46 DOI: $10.1159 / 000351458$
Jusko/Potempa/Kantyka/Bielecka/Miller/ Kalinska/Dubin/Garred/Shaw/Blom 
Table 1. Description of bacterial strains used in this study

\begin{tabular}{|c|c|c|}
\hline Bacterial strain & Description & $\begin{array}{l}\text { Reference number } \\
\text { or source }\end{array}$ \\
\hline $8325-4$ & S. aureus WT laboratory strain & laboratory stocks \\
\hline $8325-4$ aur $^{-}$ & S. aureus aur mutant, no expression of Aur metalloproteinase & 9 \\
\hline $8325-4 s s p A B C^{-}$ & $\begin{array}{l}\text { S. aureus sspABC mutant, no expression of V8 serine protease, SspB } \\
\text { cysteine protease and its inhibitor SspC }\end{array}$ & 9 \\
\hline RN6390 & S. aureus WT laboratory strain & laboratory stocks \\
\hline RN6390 scp $A^{-}$ & S. aureus scpA mutant, no expression of ScpA cysteine protease & this study \\
\hline CCUG 3709 & S. epidermidis WT laboratory strain & $\begin{array}{l}\text { culture collection, University of } \\
\text { Göteborg, Sweden }\end{array}$ \\
\hline
\end{tabular}

ide-(4-guanido)-butane); Sigma-Aldrich] or $\alpha_{2}$-macroglobulin (BioCentrum). Before use in any assay, ScpA and SspB were preactivated for $20 \mathrm{~min}$ by incubation in assay-specific buffers supplemented with 1-2 mM DTT. Purified complement proteins C3 and $\mathrm{C} 5$, and the C5a peptide, were purchased from Complement Technology.

\section{Antibodies}

The following antibodies (Abs) against human antigens were used throughout this study: rabbit polyclonal Abs (pAbs) antiC1q, -C4c and -C3d (all from DakoCytomation), goat anti-MBL (R\&D Systems), goat anti-C5 (Quidel), goat anti-factor B (FB; Complement Technology) and mouse monoclonal Abs (mAbs) anti-ficolin-2 [25] or anti-ficolin-3 [26]. Secondary pAb conjugated with horseradish peroxidase (HRP) against rabbit, goat or mouse Abs were purchased from DakoCytomation and goat antirabbit $\mathrm{F}\left(\mathrm{ab}^{\prime}\right)_{2}$ fragments conjugated with Alexa Fluor 647 were acquired from Invitrogen. Rabbit $\mathrm{F}\left(\mathrm{ab}^{\prime}\right)_{2}$ fragments conjugated with DyLight 633 were generated from rabbit pAb anti-human C1q (Dako) using a $\mathrm{F}\left(\mathrm{ab}^{\prime}\right)_{2}$ preparation kit (Pierce) and the DyLight 633 NHS ester kit (ThermoScientific).

\section{Bacterial Strains and Culture Conditions}

S. aureus strains were cultured in tryptic soy broth (Difco) or grown on tryptic soy agar plates enriched with $1 \%$ skimmed milk. For mutant strains, medium was supplemented with erythromycin ( $5 \mu \mathrm{g} / \mathrm{ml}$; Sigma-Aldrich). All bacterial strains used in this study are listed in table 1 . The RN6390 scpA-mutant was generated from previously published strains [9] using phage transduction techniques described elsewhere [9].

\section{Hemolytic Assays}

To assess activity of the classical pathway, sheep erythrocytes were washed three times with gelatin barbiturate (veronal) buffer $(\mathrm{GVB})$ with dextrose (DGVB) ${ }^{++}(2.5 \mathrm{mM}$ veronal buffer, $\mathrm{pH} 7.3$, $70 \mathrm{~mm} \mathrm{NaCl}, 140 \mathrm{~mm}$ glucose, $0.1 \%$ gelatin, $1 \mathrm{mM} \mathrm{MgCl}_{2}$ and $5 \mathrm{~mm}$ $\mathrm{CaCl}_{2}$ ). Cells were incubated with a complement-fixing $\mathrm{Ab}$ (amboceptor; Behringwerke; diluted 1:3,000 in $\mathrm{DGVB}^{++}$) at a concentration of $10^{9} \mathrm{cells} / \mathrm{ml}$ for $20 \mathrm{~min}$ at $37^{\circ} \mathrm{C}$. After two washes with $\mathrm{DGVB}^{++}, 5 \times 10^{8}$ cells $/ \mathrm{ml}$ were incubated for $1 \mathrm{~h}$ at $37^{\circ} \mathrm{C}$ with $1 \%$
NHS diluted in $\mathrm{DGVB}^{++}(150 \mu$ l total volume). Before incubation with erythrocytes, NHS was pre-incubated with various concentrations of different staphylococcal proteases for $30 \mathrm{~min}$ at $37^{\circ} \mathrm{C}$. Samples were then centrifuged and the amount of lysed erythrocytes determined by spectrophotometric measurement of released hemoglobin $(405 \mathrm{~nm})$. To assess the activity of the alternative pathway, rabbit erythrocytes were washed three times with $\mathrm{Mg}$ EGTA buffer (2.5 mM veronal buffer, pH 7.3, containing $70 \mathrm{mM}$ $\mathrm{NaCl}, 140 \mathrm{~mm}$ glucose, $0.1 \%$ gelatin, $7 \mathrm{mM} \mathrm{MgCl}_{2}$ and $10 \mathrm{mM}$ EGTA). Erythrocytes at a concentration of $5 \times 10^{8}$ cells $/ \mathrm{ml}$ were then incubated for $1 \mathrm{~h}$ at $37^{\circ} \mathrm{C}$ with $2 \%$ NHS diluted in Mg-EGTA buffer $(150 \mu$ l total volume). The assay was modified for Aur using $4 \% \mathrm{C} 1 \mathrm{q}$-depleted human serum diluted in $\mathrm{GVB}^{++}$buffer $(5 \mathrm{mM}$ veronal buffer, $\mathrm{pH} 7.3,140 \mathrm{mM} \mathrm{NaCl}, 0.1 \%$ gelatin, $1 \mathrm{mM} \mathrm{MgCl}$ and $5 \mathrm{mM} \mathrm{CaCl}_{2}$ ). In both variants of the alternative pathway assay, NHS was pre-incubated with different staphylococcal proteases for $15 \mathrm{~min}$ at $37^{\circ} \mathrm{C}$. Samples were then centrifuged and the amount of erythrocyte lysis determined spectrophotometrically (405 nm).

\section{Complement Activation Assays}

Microtiter plates (Maxisorp; Nunc) were incubated overnight at $4^{\circ} \mathrm{C}$ with $50 \mu \mathrm{l}$ of a solution containing $2 \mu \mathrm{g} / \mathrm{ml}$ human aggregated IgG (Immuno), $100 \mu \mathrm{g} / \mathrm{ml}$ mannan (M-7504; Sigma-Aldrich), $20 \mu \mathrm{g} / \mathrm{ml}$ zymosan (Z-4250; Sigma-Aldrich) in $75 \mathrm{~mm}$ sodium carbonate (pH 9.6) or $10 \mu \mathrm{g} / \mathrm{ml}$ acetylated BSA (AppliChem; acetylated as described [27]) in PBS. Between each step of the procedure, plates were washed four times with $50 \mathrm{mM}$ Tris- $\mathrm{HCl}, 150$ $\mathrm{mM} \mathrm{NaCl}$ and $0.1 \%$ Tween 20 (pH 7.5). Wells were blocked with $1 \%$ BSA in PBS for $2 \mathrm{~h}$ at room temperature. NHS (classical and lectin pathway) was diluted in $\mathrm{GVB}^{++}$buffer and used at a concentration of $2 \%$ for measurement of deposition of $\mathrm{C} 1 \mathrm{q} ; 1 \%$ for $\mathrm{C} 3 \mathrm{~b}$ and $\mathrm{C} 4 \mathrm{~b}$ in the classical pathway; $2 \%$ for $\mathrm{C} 3 \mathrm{~b}, \mathrm{C} 4 \mathrm{~b}$, ficolin-2 and ficolin-3 in the lectin pathway, and $4 \%$ for MBL. For the alternative pathway, 3\% NHS in Mg-EGTA (all proteases except Aur) or 4\% $\mathrm{C} 1 \mathrm{q}$-deficient serum in $\mathrm{GVB}^{++}$(Aur) were used for the deposition of C3b, FB and C5b. These concentrations were chosen on the basis of initial titrations. The serum used was mixed with various concentrations of different staphylococcal proteases, pre-incubated for $25 \mathrm{~min}$ (NHS) or $15 \mathrm{~min}$ (C1q-depleted serum) at $37^{\circ} \mathrm{C}$ and incubated in the wells of microtiter plates for $45 \mathrm{~min}$ at $37^{\circ} \mathrm{C}$ for 
$\mathrm{C} 1 \mathrm{q}$ and $\mathrm{MBL}, 20 \mathrm{~min}$ at $37^{\circ} \mathrm{C}$ for $\mathrm{C} 3 \mathrm{~b}$ and $\mathrm{C} 4 \mathrm{~b}$ (classical and lectin pathway), and $35 \mathrm{~min}$ for $\mathrm{C} 3 \mathrm{~b}, \mathrm{FB}$ and $\mathrm{C} 5 \mathrm{~b}$ (alternative pathway). Complement activation was assessed by detecting deposited complement factors using specific Abs against C1q, C4b, C3d, FB, C5, MBL, ficolin-2 and ficolin-3, each diluted in blocking buffer. Bound Abs were detected with HRP-labeled anti-rabbit, anti-goat or anti-mouse secondary pAbs. Bound HRP-labeled pAbs were detected with 1,2-phenylenediamine dihydrochloride tablets ( $\mathrm{Da}$ koCytomation), with absorbance measured at $490 \mathrm{~nm}$.

\section{Deposition of C1q on Bacteria}

Staphylococcus epidermidis CCUG 3709 and S. aureus 8325-4 were grown in tryptic soy broth overnight, harvested by centrifugation, washed once in PBS, adjusted to an optical density (OD) 600 of 1.0 and incubated with $10 \mu \mathrm{M}$ CFSE (Sigma-Aldrich) for $20 \mathrm{~min}$ in the dark. After incubation, bacteria were washed once and adjusted to an $\mathrm{OD}_{600}$ of 0.6 in $\mathrm{GVB}++$. NHS $(6 \%)$ was treated with different concentrations of Aur and V8 for 25 min at $37^{\circ} \mathrm{C}$, after which time $80-\mu \mathrm{l}$ aliquots of these samples were mixed with an 80 $\mu \mathrm{l}$ solution of bacteria and incubated for $45 \mathrm{~min}$ at $37^{\circ} \mathrm{C}$ (3\% NHS final concentration). Thereafter, cells were washed twice in FACS buffer (50 mM HEPES, $100 \mathrm{~mm} \mathrm{NaCl}, \mathrm{pH} 7.4,1 \%$ BSA and $30 \mathrm{~mm}$ $\mathrm{NaN}_{3}$ ). C1q deposition was assessed by incubation of cells with rabbit anti-human $\mathrm{C} 1 \mathrm{q} \mathrm{F}(\mathrm{ab})_{2}$ fragments conjugated with DyLight 633 for $45 \mathrm{~min}$. The geometric mean fluorescence intensity of DyLight 633 was calculated for 25,000 CFSE-positive cells using FlowJo software (Tree Star).

\section{Degradation Assays}

C3 and C5 (0.2 $\mu \mathrm{M}$ each) were incubated with S. aureus proteases at concentrations ranging from 0.06 to $2 \mu \mathrm{M}$. Incubations were carried out for $2.5 \mathrm{~h}$ in $50 \mathrm{~mm}$ HEPES ( $\mathrm{pH} 7.4$ ), $150 \mathrm{mM} \mathrm{NaCl}$ and $5 \mathrm{mM} \mathrm{CaCl}_{2}$ buffer at $37^{\circ} \mathrm{C}$. Proteins were separated by SDS-PAGE electrophoresis using standard Laemmli procedures and $12 \%$ gels. Prior to electrophoresis, samples were boiled for $5 \mathrm{~min}$ at $95^{\circ} \mathrm{C}$ in a reducing sample loading buffer containing $25 \mathrm{mM}$ DTT and $4 \%$ SDS. Separated proteins were visualized by staining with silver salts.

\section{Chemotaxis Assays}

For C5a chemotaxis assays, plasma was used because serum may contain C5a and C5adesArg, which are produced during blood coagulation [28]. Blood was collected with $50 \mu \mathrm{g} / \mathrm{ml} \mathrm{Re}$ fludan (Pharmion), centrifuged at 2,000 rpm for $10 \mathrm{~min}$, with plasma stored in aliquots at $-80^{\circ} \mathrm{C}$. To isolate neutrophils, human blood from healthy volunteers was drawn in heparinized blood collection tubes (BD Vacutainer) and left for $15 \mathrm{~min}$ at room temperature. Subsequently, blood was layered on an equal volume of Histopaque-1119 (Sigma-Aldrich) and centrifuged for $20 \mathrm{~min}$ at $800 \mathrm{~g}$ (room temperature). The polymorphonuclear cell-rich interphase was washed once in $0.5 \%$ human albumin (Sigma-Aldrich) in PBS (HyClone), placed onto a 65-85\% Percoll gradient (GE Healthcare) and centrifuged for $20 \mathrm{~min}$ at $800 \mathrm{~g}$ (room temperature). Cells dispersed in the 70-75\% Percoll layers were collected, washed once in $0.5 \%$ albumin solution and adjusted to a concentration of $1.0 \times 10^{7}$ cells $/ \mathrm{ml}$ in a PBS solution of $4 \%$ heat-inactivated $\left(30 \mathrm{~min}, 56^{\circ} \mathrm{C}\right)$ Refludan-treated human plasma. The purity of neutrophils ( $>70 \%$ ) was determined by flow cytometry using staining with anti-CD16 mAb labeled with allophycocyanin (ImmunoTools).
Chemotactic activity was measured in a disposable 96-well cell migration system with $3-\mu \mathrm{m}$ polycarbonate membranes (ChemoTx; Neuro Probe). Serial dilutions of proteases were incubated with $4 \%$ heat-inactivated human plasma (the same as for neutrophil suspensions) for $30 \mathrm{~min}$ at $37^{\circ} \mathrm{C}$ and thereafter applied to the wells of the ChemoTx microplate. Purified human C5a (Complement Technology) at $12.5 \mathrm{nM}$, diluted in $4 \%$ heat-inactivated human plasma, served as a positive control, whereas plasma alone, proteases (at maximal concentrations used in the samples with plasma) diluted in PBS and PBS alone were used as negative controls. A volume of $50 \mu \mathrm{l}$ of $1.0 \times 10^{7}$ neutrophils $/ \mathrm{ml}$ in $4 \%$ heatinactivated human plasma was applied to each well of the filter top. The microplate was incubated for $60 \mathrm{~min}$ at $37^{\circ} \mathrm{C}$ in humidified air with $5 \% \mathrm{CO}_{2}$ before the membrane was removed. Samples were transferred to a new flat-bottom 96-well plate (Sterilin) and mixed with $30 \mu \mathrm{l}$ of cell lysis buffer [ $0.5 \%$ hexadecyl trimethyl ammonium bromide (Sigma-Aldrich) in PBS]. Similarly, $30 \mu \mathrm{l}$ of cell lysis buffer were added to all wells of the emptied ChemoTx microplate. Both plates were incubated for $30 \mathrm{~min}$ at room temperature, and subsequently the solutions from corresponding wells were pooled together. The activity of neutrophil-associated myeloperoxidase was detected in lysates using 1,2-phenylenediamine dihydrochloride tablets, and absorbance was recorded at $490 \mathrm{~nm}$.

\section{Whole Blood Killing Assay}

$S$. aureus strains (table 1) were grown overnight in $10 \mathrm{ml}$ of tryptic soy broth. Bacteria were harvested for $5 \mathrm{~min}$ at 3,000 $\mathrm{g}$, and the culture supernatants were collected for subsequent use to make bacterial suspensions for the assay. Bacteria were re-inoculated to the respective supernatants at $\mathrm{OD}_{600}$ of 0.15 for the $8325-4$ wildtype $(\mathrm{WT})$ strain $\left(1.0 \times 10^{8} \mathrm{CFU} / \mathrm{ml}\right)$ and its mutants, or an $\mathrm{OD}_{600}$ of $0.4\left(0.5 \times 10^{8} \mathrm{CFU} / \mathrm{ml}\right)$ for strain RN6390 and its mutant. Forty microliters of these cultures were mixed with $360 \mu$ l of freshly collected human blood anticoagulated with Refludan, a recombinant hirudin anticoagulant that does not affect complement activation [29], and incubated at $37^{\circ} \mathrm{C}$ for $20 \mathrm{~min}$. After incubation, aliquots were removed, serially diluted and plated onto tryptic soy agar. Bacterial survival was calculated via colony enumeration.

Statistical Analysis

One-way ANOVA (InStat) was used to calculate $\mathrm{p}$ values to estimate whether the observed differences between experimental results were statistically significant.

\section{Results}

\section{Staphylococcal Proteases Diminish Complement} Activity in Human Serum

In order to verify if staphylococcal proteases inhibit human complement, purified enzymes were incubated with human serum at various concentrations, and hemolytic assays were used to assess activity of the classical and alternative pathways of complement in pretreated sera. ScpA, SspB and V8 were found to be efficient inhibitors of the classical pathway, with $>70 \%$ inhibition observed at a $1-\mu \mathrm{M}$ concentration (fig. 1a, b), whereas SplD and 
Fig. 1. Staphylococcal proteases diminish the hemolytic activity of human serum. a-c Classical pathway. NHS (1\%) was supplemented with various concentrations of proteases and pre-incubated for $30 \mathrm{~min}$ at $37^{\circ} \mathrm{C}$, after which time sheep erythrocytes sensitized with Abs and diluted in $\mathrm{GVB}^{++}$ were added. d-f Alternative pathway. 2\% NHS in Mg-EGTA (d, e) or C1q-depleted human serum (4\%) in $\mathrm{GVB}^{++}$(f) were preincubated with increasing concentrations of proteases for $15 \mathrm{~min}$ at $37^{\circ} \mathrm{C}$. Serum was then added to sheep $(\mathbf{a}-\mathbf{c})$ or rabbit $(\mathbf{d}-\mathbf{f})$ erythrocytes diluted in their respective buffers. a-f After a 1-hour incubation, the degree of lysis was estimated by measurement of released hemoglobin (absorbance at $405 \mathrm{~nm}$ ). Lysis obtained in the absence of proteases was set as $100 \%$. An average of three independent experiments is presented with bars indicating SD.

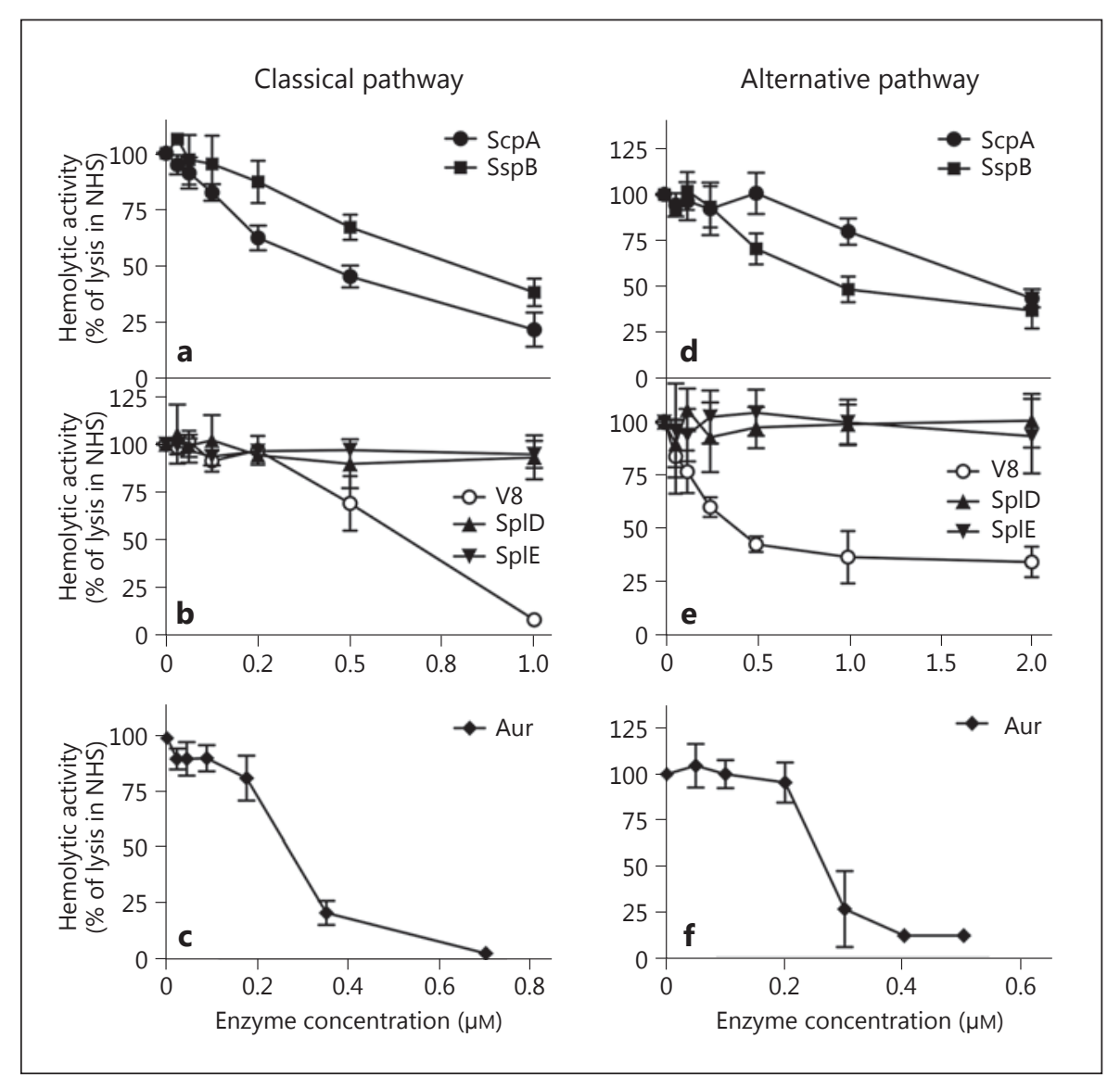

SplE were devoid of such activity (fig. 1b). The metalloproteinase Aur was the most effective, inhibiting the classical pathway by $98 \%$ when present at low micromolar concentrations $(0.7 \mu \mathrm{M}$; fig. $1 \mathrm{c})$.

All proteases that exerted an inhibitory effect on the classical pathway also inhibited the alternative pathway (fig. 1d-f). ScpA and SspB (fig. 1d), as well as V8 protease (fig. 1e), inhibited the alternative pathway by at least $50 \%$ when present at $2 \mu \mathrm{M}$. Aur again was the most effective inhibitor, however it has to be considered that to assess its effect on the alternative pathway, a modified hemolytic assay was used since this metalloproteinase requires calcium ions for activity, while the standard buffer used for alternative pathway assays contains EGTA, which will chelate calcium. Therefore, $\mathrm{GVB}^{++}$buffer and C1q-depleted NHS were used for incubation with rabbit erythrocytes. Under such conditions, Aur inhibited the alternative pathway (fig. 1f) by $90 \%$ at $0.5 \mu \mathrm{M}$. SplD and SplE did not affect the alternative pathway in any regard (fig. 1e). In addition, V8 activity was tested in both types of the alternative pathway hemolytic assay, with no sig-

Staphylococcal Proteases Inhibit Complement nificant difference found, proving that these two methods are comparable.

\section{Staphylococcal Proteases Interfere with All Three}

Activation Pathways by Degrading Multiple Key

\section{Complement Factors}

Each complement pathway is a cascade of events activated in a consecutive manner. In order to assess which complement factor(s) were affected by staphylococcal proteases, a microtiter-plate-based assay was used. In this assay, depending on the pathway analyzed, complement activation was initiated by various ligands, and the deposition of successive complement factors was detected with specific Abs. In the case of the classical pathway, complement activation was initiated by aggregated human immunoglobulins. For the assessment of the lectin pathway, we used plates coated with mannan (MBL) or acetylated BSA (ficolins). The alternative pathway was activated by immobilized zymosan and the assay was performed using NHS in Mg-EGTA buffer (for all proteases except Aur) or $\mathrm{Clq}$-deficient serum in $\mathrm{GVB}^{++}$buffer (Aur). 


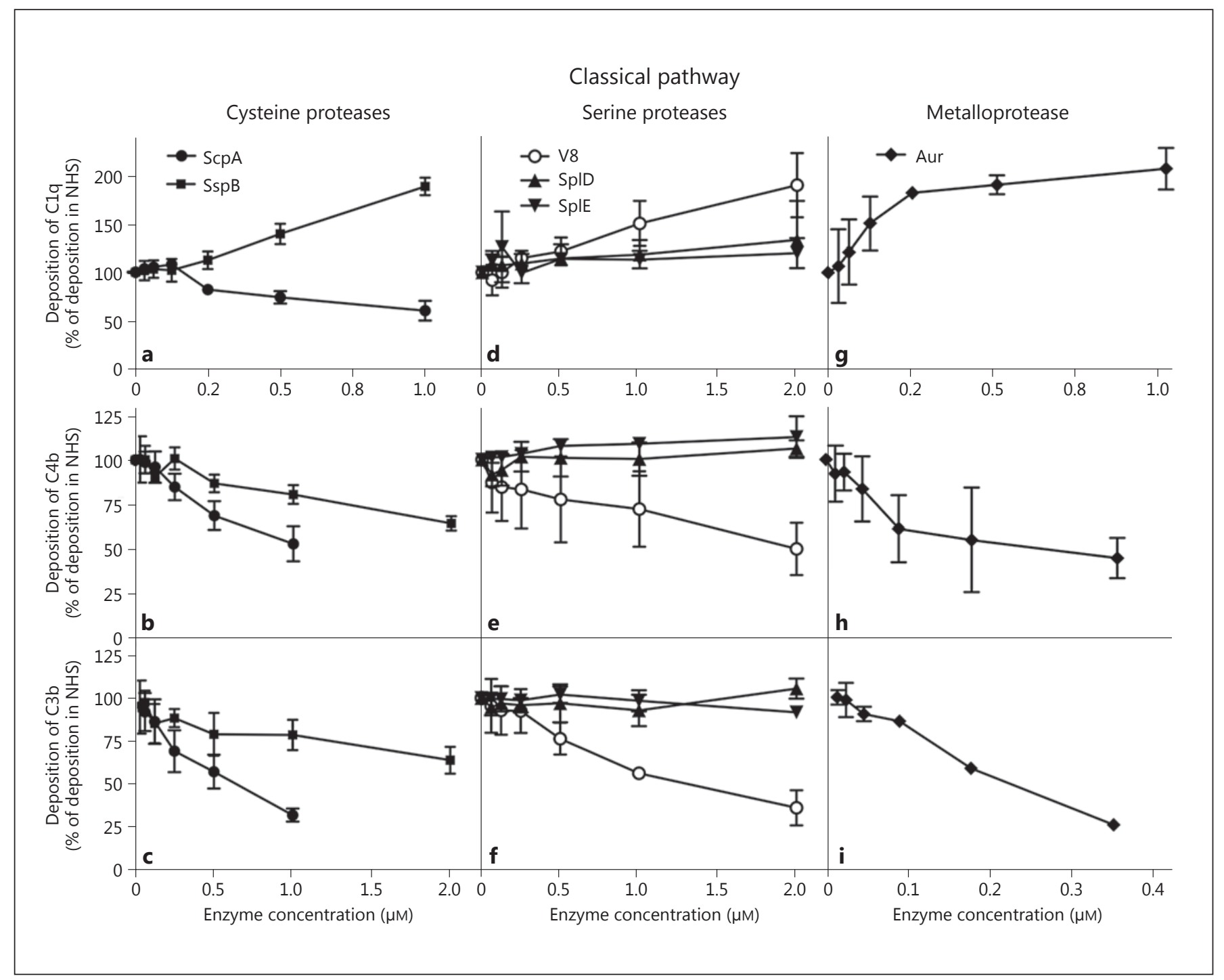

Fig. 2. Staphylococcal proteases inhibit the classical pathway. Serially diluted proteases were incubated for 25 min with 2 (C1q) or $1 \%(\mathrm{C} 3 \mathrm{~b}, \mathrm{C} 4 \mathrm{~b})$ NHS diluted in $\mathrm{GVB}^{++}$and added to microtiter plates coated with IgGs. After 20 (C3b, C4b) and $45 \mathrm{~min}$ (C1q) of incubation, plates were washed and deposited $\mathrm{C} 1 \mathrm{q}(\mathbf{a}, \mathbf{d}, \mathbf{g}), \mathrm{C} 4 \mathrm{~b}$ (b, e, h) and C3b (c, f, i) were detected with specific pAbs. Absorbance obtained in the absence of protease was set as 100\%. An average of three independent experiments is presented with bars indicating SD.
Fig. 3. Staphylococcal proteases inhibit the lectin pathway of complement. Serial dilutions of proteases were incubated for $25 \mathrm{~min}$ with 4 (MBL) or $2 \%$ (C3b, C4b, ficolin-2 and ficolin-3) NHS diluted in $\mathrm{GVB}^{++}$and added to microtiter plates coated with mannan (MBL, C3b and C4b) or acetylated BSA (ficolins). After 20 (C3b, $\mathrm{C} 4 \mathrm{~b}$ ) or $45 \mathrm{~min}$ (MBL, ficolin-2, ficolin-3) of incubation, plates were washed and deposited MBL (a, f, $\mathbf{k})$, ficolin-2 (b, g, I), ficolin-3 (c, h, m), C4b (d, i, n) and C3b $(\mathbf{e}, \mathbf{j}, \mathbf{o})$ were detected with specific Abs. Absorbance obtained in the absence of protease was set as $100 \%$. An average of three independent experiments is presented with bars indicating SD. 


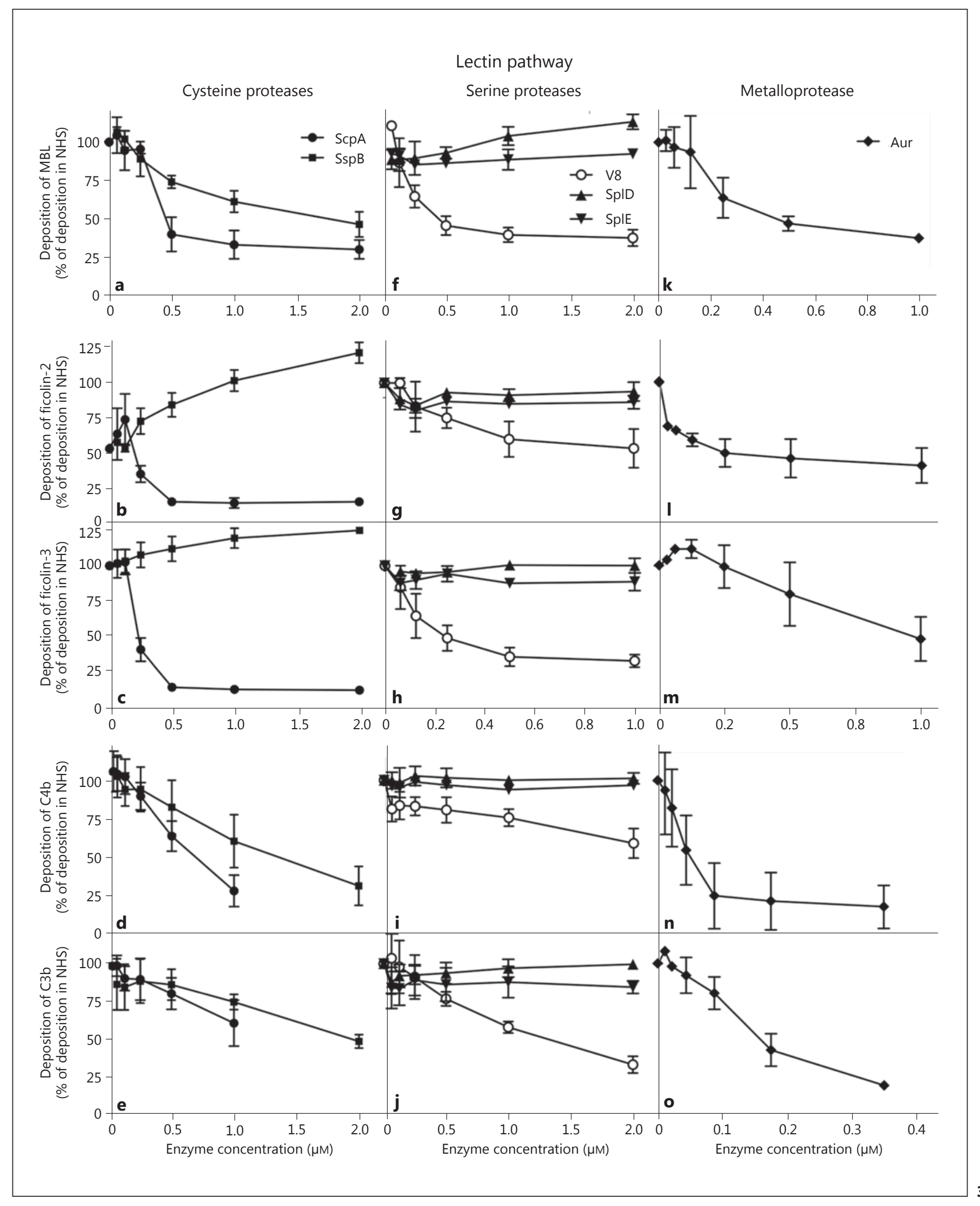




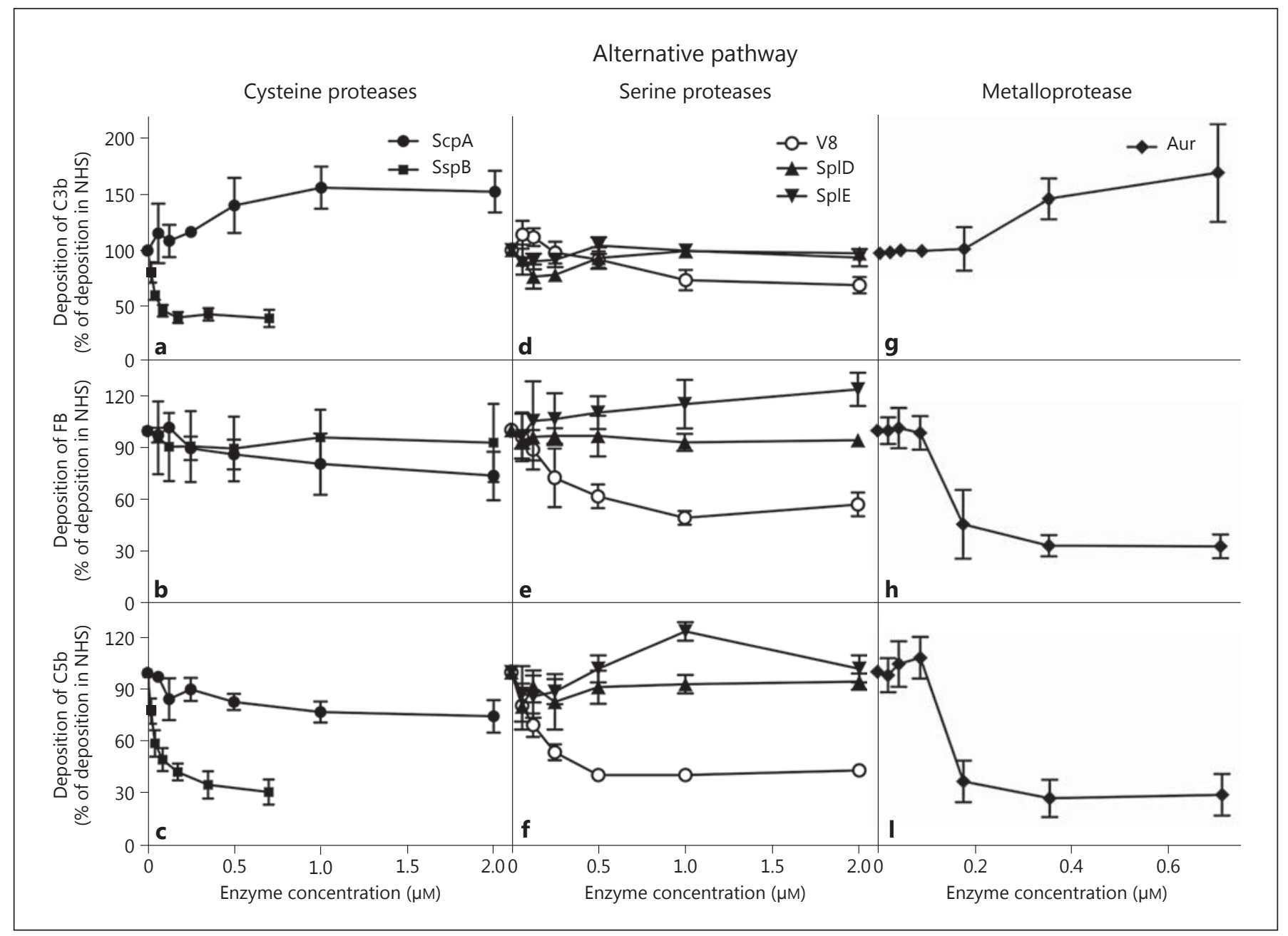

Fig. 4. Staphylococcal proteases inhibit the alternative pathway of complement. Serial dilutions of proteases were incubated with $3 \%$ NHS in Mg-EGTA for 25 (a-f) or 15 min with 4\% C1q-depleted serum in $\mathrm{GVB}^{++}(\mathbf{g}-\mathbf{i})$. Samples were then added to microtiter plates coated with zymosan. After 35 min of incubation, plates

For the cysteine protease ScpA (fig. 2-4, left panels: cysteine proteases), we found that in the classical pathway, the deposition of C1q was decreased by up to $40 \%$ in the presence of $1 \mu \mathrm{M}$ of this enzyme (fig. $2 \mathrm{a}$ ). Consequently, deposition of $\mathrm{C} 4 \mathrm{~b}$ (fig. 2b) and C3b (fig. 2c) was also decreased by $>50 \%$ at $1 \mu \mathrm{M}$. ScpA also attenuated the lectin pathway as it inhibited the deposition of all three collectins: MBL (fig. 3a), ficolin-2 (fig. 3b) and ficolin-3 (fig. 3c), as well as all of the ensuing complement factors, such as C4b (fig. 3d) and C3b (fig. 3e). Surprisingly, in the alternative pathway, ScpA caused a significant increase in the deposition of C3b (fig. 4a), whereas deposition of FB (fig. 4b) and C5b (fig. 4c) were relatively unaffected. were washed, and deposition of C3b (a, d, $\mathbf{g}), \mathrm{FB}(\mathbf{b}, \mathbf{e}, \mathbf{h})$ or C5b $(\mathbf{c}, \mathbf{f}, \mathbf{i})$ was detected with specific polyclonal Abs. Absorbance obtained in the absence of protease was set as $100 \%$. An average of three independent experiments is presented with bars indicating SD.

The other cysteine protease of S. aureus, SspB (fig. 2-4, left panels: cysteine proteases), displayed a distinct mode of action towards complement. For the classical pathway, deposition of $\mathrm{Clq}$ from human serum was enhanced in the presence of SspB (fig. 2a). Downstream to C1q, we found a slight inhibition of the pathway, with $\mathrm{C} 4 \mathrm{~b}$ deposition decreased by $30 \%$ at $2 \mu \mathrm{M}$ protease (fig. $2 \mathrm{~b}$ ). Accordingly, C3b deposition was also decreased (fig. 2c). The interference of SspB with the lectin pathway also appeared on the level of collectins, as for ScpA. However, in this case only MBL was sensitive to degradation by SspB (fig. 3a), whereas deposition of ficolins was greatly enhanced (by up to $120 \%$ ) for ficolin-2 (fig. 3b) and slightly 


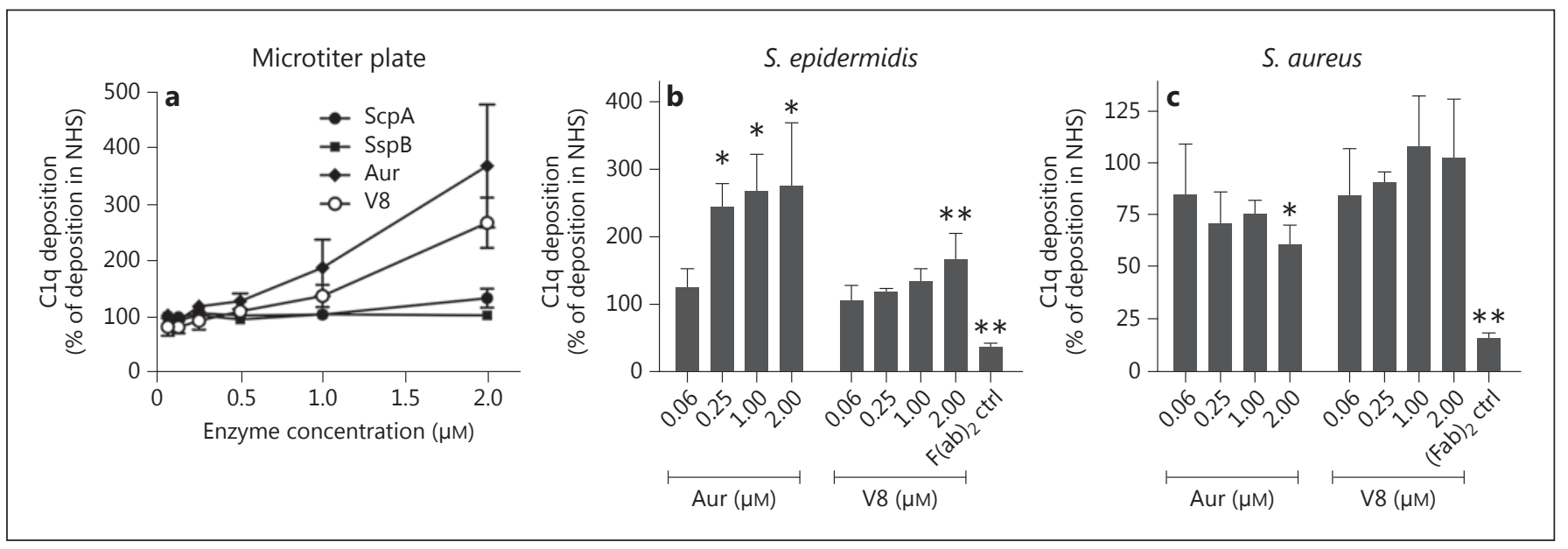

Fig. 5. Staphylococcal proteases Aur and V8 cause activation and deposition of $\mathrm{C1q}$ on microtiter plates as well as commensal bacteria. a Microtiter plates were blocked with BSA and incubated for 45 min with 5\% NHS containing various concentrations of proteases. Deposited C1q was detected with a specific Ab. Absorbance obtained for NHS in the absence of protease was set as $100 \%$. An average of three independent experiments is presented with bars indicating SD. S. epidermidis CCUG 3709 (b) and S. aureus 8325-
4 (c) were incubated with NHS (3\%) and different concentrations of proteases. Deposition of C1q was quantified using flow cytometry with specific $\mathrm{F}(\mathrm{ab})_{2}$ fragments, and the absorbance obtained in the absence of proteases was set as $100 \%$. An average of three independent experiments is presented with bars indicating SD. Statistical significance of the observed differences was estimated using one-way ANOVA and a Dunnett post hoc test $(* \mathrm{p}<0.05$, ** $\mathrm{p}<0.01)$. ctrl = Control. (by up to 25\%) for ficolin-3 (fig. 3c). The deposition of consecutive factors, C4b (fig. 3d) and C3b (fig. 3e), was consequently inhibited. In the alternative pathway, we found that SspB strongly inhibited the deposition of $\mathrm{C} 3 \mathrm{~b}$ (fig. 4a) and C5b (fig. 4c), while there was no effect on FB (fig. 4b).

The V8 serine protease (fig. 2-4, middle panels: serine proteases), similarly to $\mathrm{SspB}$, also caused an increase in the deposition of $\mathrm{Clq}$ (fig. 2d). V8 also reduced the deposition of C4b (fig. 2e) and C3b (fig. 2f). Like ScpA, V8 was found to inhibit the deposition of all the lectin pathway collectins: MBL (fig. 3f), ficolin-2 (fig. 3g) and ficolin-3 (fig. 3h), and consequently decreased C4b (fig. 3i) and $\mathrm{C} 3 \mathrm{~b}$ (fig. $3 \mathrm{j}$ ) deposition. In the alternative pathway, we found that V8 reduced the deposition of $\mathrm{C} 3 \mathrm{~b}$ (fig. 4d) as well as FB (fig. 4e) and C5b (fig. 4f). The other two serine proteases, SplD and SplE, did not have any effect on any pathway (fig. 2-4, middle panels).

The metalloproteinase Aur (fig. 2-4, right panels: metalloprotease), like SspB and V8, caused enhanced deposition of the classical pathway initiator C1q (fig. $2 \mathrm{~g}$ ) and then inhibited deposition of C4b (fig. 2h) and C3b (fig. 2i) at a relatively low concentration $(350 \mathrm{nM})$. In the lectin pathway, we found that Aur, like ScpA and V8, decreased the deposition of MBL, ficolin-2 and ficolin-3 (fig. 3k$\mathrm{m}$ ), which was followed by a decrease in C4b (fig. $3 \mathrm{n}$ ) and
C3b deposition (fig. 3o). Surprisingly, however, there was a significant deposition of $\mathrm{C} 3 \mathrm{~b}$ in the alternative pathway in the presence of Aur (fig. 4g), while the deposition of FB (fig. 4h) and C5 (fig. 4i) was efficiently decreased. The data regarding C3b deposition via the classical and lectin pathways are in agreement with previously published findings [18]. However, we do see the inhibition of these pathways upstream to $\mathrm{C} 3 \mathrm{~b}$, already at the level of $\mathrm{C} 4 \mathrm{~b}$ formation, which is in contrast with the statement in a previous study [18], where the authors did not observe such an inhibition.

\section{Staphylococcal Proteases Aur and V8 Cause Activation and Deposition of $C 1$ in the Absence of Any Activator}

In classical pathway assays, we observed that SspB, V8 and Aur did not inhibit the deposition of C1q, but rather enhanced its deposition on aggregated IgG over the entire range of enzyme concentrations tested. When human serum was incubated with ScpA, SspB, V8 and Aur in the absence of any immobilized $\mathrm{C} 1$ activator, we found that Aur and V8 caused increased deposition of C1q on empty microtiter plates blocked with BSA (fig. 5a). This effect was not observed for SspB, although elevated deposition of C1q on aggregated IgGs was found previously (fig. 2a). In addition, Aur and V8 were also found to cause deposi- 

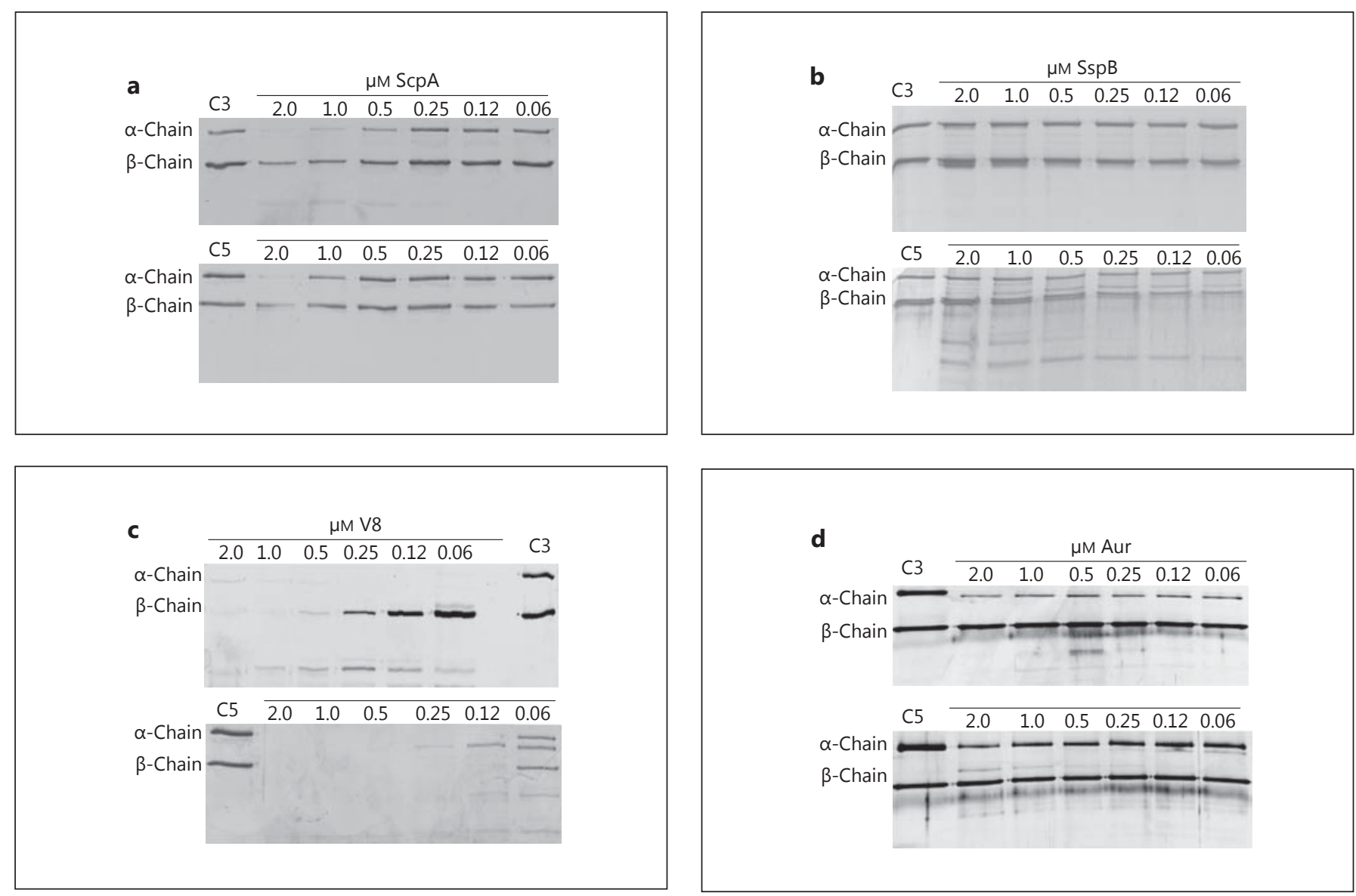

Fig. 6. Staphylococcal proteases degrade C3 and C5. C3 and C5 ( $0.2 \mu \mathrm{M}$ each) were incubated with serial dilutions of ScpA (a), SspB (b), V8 (c) and Aur (d). Incubations were carried out for $2.5 \mathrm{~h}$ at $37^{\circ} \mathrm{C}$, with proteins then separated by SDS-PAGE. All gels were stained with silver salts.

tion of C1q on bacterial surfaces. To this end, S. epidermidis was incubated with NHS containing Aur at different concentrations, and the deposition of C1q was measured using flow cytometry. We found that the addition of Aur to NHS caused a large increase in C1q deposition on the surface of S. epidermidis that mimicked results obtained using microtiter plates (fig. 5b). We observed the same effect using V8, although to a lesser extent (fig. 5b). In contrast, when $S$. aureus was tested in the same conditions, we found that Aur caused a slight reduction in $\mathrm{Clq}$ deposition on the surface of the pathogen, whereas V8 had no effect (fig. 5c). Taken together, our results show that Aur and V8 are able to cause deposition of active C1 complexes on normally non-activating surfaces, such as BSA-coated plastic, and, in addition, can cause increased $\mathrm{C} 1 \mathrm{q}$ deposition on bacterial surfaces. This increased $\mathrm{Clq}$ deposition is more likely to occur on commensal bacteria, such as $S$. epidermidis, rather than $S$. aureus itself, on which its own protease Aur seems to moderately inhibit C1q opsonization.

\section{Proteases of S. aureus Degrade Complement Factors C3 and C5 and Generate Biologically Active Anaphylatoxins}

To assess the cleavage pattern of different proteases, purified C3 and C5 were incubated with proteases at various molar ratios. Proteins were then separated by SDSPAGE and visualized using silver staining. Both, $\mathrm{C} 3$ and C5 are composed of covalently linked $\alpha$ - and $\beta$-chains. Different cleavage patterns were observed for all of the proteases tested. Specifically, ScpA degraded both C3 and $\mathrm{C} 5$, but only at the highest concentrations, and apparently acted on both chains of the molecules, with some preference toward the $\alpha$-chain (fig. 6a). Interestingly, 
SspB specificity did not cause any degradation of purified C3 (fig. 6b), but efficiently cleaved C3b deposited on the surface of plates coated with mannan (data not shown). In addition, it caused an efficient degradation of C3met (C3 treated with methylamine, resembling C3b; data not shown), which further proves SspB specificity for the activated form of C3, C3b. Importantly, SspB showed limited degradation of the C5 a-chain (fig. 6b). Under the same conditions, V8 caused almost complete degradation of $\mathrm{C} 3$ and $\mathrm{C} 5$, even at the lowest concentration tested, implicating multiple cleavage sites in both chains of the molecules (fig. 6c). Aur, as reported previously [18], specifically degraded the $\alpha$-chain of $\mathrm{C} 3$ and released a band corresponding to $\mathrm{C} 3 \mathrm{~b}$ (fig. 6d). Surprisingly, we also found that Aur acted on the $\alpha$-chain of $C 5$, which was cleaved in a dose-dependent manner (fig. 6d). SplD and SplE, as expected, did not show any degradation of either of the complement proteins (data not shown). An analysis of C5 cleavage patterns by SspB (fig. 6b) and Aur (fig. 6d) indicated that they were perhaps able to release a band with a molecular mass corresponding to C5b. Therefore, we assessed if incubation of these proteases with heat-inactivated human plasma would result in the generation of the chemotactic peptide $\mathrm{C} 5 \mathrm{a}$, which would subsequently attract purified human neutrophils. ScpA and V8 were also tested in this assay, with purified C5a serving as a positive control. Surprisingly, both staphopains, ScpA and SspB, as well as Aur were able to stimulate the migration of neutrophils toward heat-inactivated plasma, indicating the release of anaphylatoxins (fig. 7a). The peak chemotactic activity (comparable to the C5a-positive control) produced by ScpA was at $1.5 \mu \mathrm{M}$, and at higher concentrations of the enzyme, migration began to decline marginally. The C5a release by ScpA was apparently not accompanied by the generation of intact C5b (most probably once released, the C5b was degraded further to smaller peptides; fig. 6a). For SspB, peak migration was achieved at $5 \mu \mathrm{M}$, with higher concentrations not tested since at $5 \mu \mathrm{M}$ some background migration occurred towards SspB alone. To our surprise, Aur was the most active in releasing biologically active C5a, as already $120 \mathrm{~nm}$ protease produced a peak in chemotactic activity, with a pronounced decline in migration at higher metalloprotease concentrations. V8 did not cause any release of chemotactic activity (data not shown), indicating that although a band corresponding to C5b can be seen transiently at very low concentrations, the cleavage products (including potential $\mathrm{C} 5 \mathrm{a}$ ) are most probably degraded rapidly to smaller fragments.

Staphylococcal Proteases Inhibit

Complement
Expression of Proteases by S. aureus Contributes to

\section{Enhanced Survival in Whole Human Blood}

In order to verify the effect of proteases on the survival of $S$. aureus in human blood, we studied the survival of strains lacking different proteases compared to WT. For this purpose, $S$. aureus strains (table 1) grown in tryptic soy broth overnight (under conditions that yielded the highest detectable proteolytic activity in the medium of WT strains; data not shown) were incubated for $20 \mathrm{~min}$ at $37^{\circ} \mathrm{C}$ in fresh human blood, and survival was assessed by colony counting from serial dilutions (fig. $7 \mathrm{~b}$ ). Mutant strains of 8325-4 lacking different proteases, or combinations of proteases, showed reduced survival compared to the WT strain, indicating the involvement of proteolytic enzymes in resistance to killing by human blood. This decreased survival was significant for all mutants, with the most significant effect observed for those lacking Aur. Strains lacking ScpA in RN6390 did not show significantly different survival compared to WT.

\section{Discussion}

The role of $S$. aureus proteases in the virulence of this bacterium has been documented in numerous studies showing that they are able to interact with host defense mechanisms and tissue components. The results of the current study demonstrate that four major proteases of $S$. aureus provide a powerful strategy for defense against complement. Importantly, the protease genes are highly conserved among clinical S. aureus strains, although under in vitro conditions downregulation of their expression has been observed in some clinical isolates [30]. In contrast, $S$. aureus grown in serum significantly increases the production of proteases [31]. The major control of expression and activity of extracellular proteases, similar to other secreted virulence factors of $S$. aureus, is based on the interplay of two global regulators. Positive regulation is provided by the accessory gene regulator (agr) quorum-sensing system $[32,33]$, whereas the pleiotropic virulence determinant regulator, SarA, is responsible for protease repression [34]. According to the generally accepted hypothesis, dissemination of $S$. aureus takes place via transition from adhesive (promoted by sarA) to migratory/invasive phenotypes (promoted by agr), producing various extracellular proteins. This process is dependent on, amongst other things, proteolytic enzymes, which cleave tissue adhesion molecules $[35,36]$. In the adhesive form, S. aureus must deal with complement factors that can be produced locally on the skin/epithelium

J Innate Immun 2014;6:31-46

DOI: $10.1159 / 000351458$ 
a

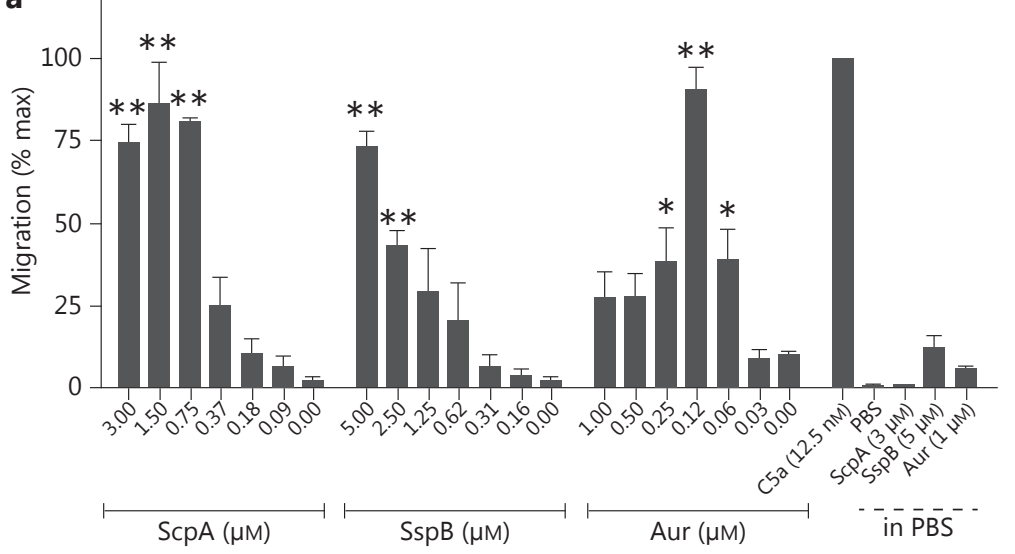

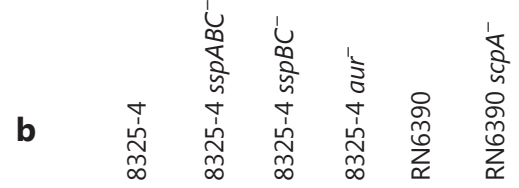

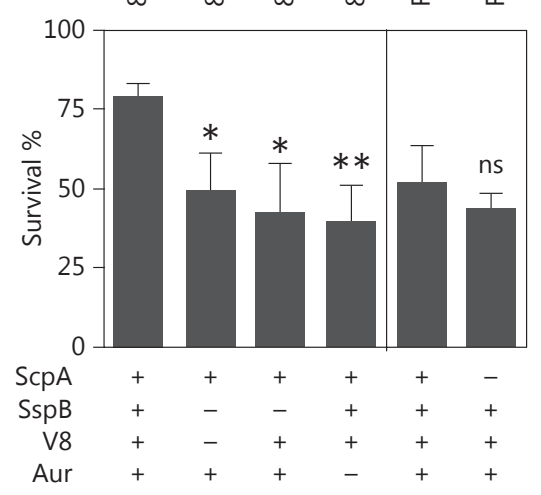

Fig. 7. Proteases of $S$. aureus generate biologically active C5a and their expression contributes to survival in whole human blood. a Increasing concentrations of ScpA, SspB and Aur were incubated with $4 \%$ heat-inactivated human plasma and then placed in the wells of ChemoTx microplates. Neutrophil migration was measured after $1 \mathrm{~h}$ as activity of neutrophil-associated myeloperoxidase. PBS and proteases alone were used as negative controls, and human C5a (12.5 nM) was the positive control. Absorbance obtained for the highest migration in the assay, observed with the positive control, was set as $100 \%$. An average of three independent experiments is presented with error bars indicating SD. Statistical significance was determined using one-way ANOVA and a Dun-

$[37,38]$, yet dissemination into the bloodstream exposes the bacterium to far more challenging conditions, especially in terms of complement activation. Herein we show that four of the major proteases of $S$. aureus, the staphopains (ScpA and SspB), V8 and Aur, may help to successfully evade complement.

In general, we found that all pathways of complement activation were attenuated by $S$. aureus, although there appears to be more specific effects of these proteases on complement, which are worth underscoring. Specifically, we demonstrate that the proteases of $S$. aureus decrease deposition of the collectins, MBL and ficolins (fig. 3). MBL has been proposed as a first-line defense mechanism against $S$. aureus [39], whilst ficolin-2 binds lipoteichoic acid produced by this bacterium [40]. Our results show that these recognition and complement activation pathways might be corrupted by staphylococcal proteases. Interestingly, we found that the deposition of a classical nett post hoc test $\left({ }^{*} \mathrm{p}<0.05,{ }^{* *} \mathrm{p}<0.01,{ }^{* * *} \mathrm{p}<0.001\right)$, and calculated compared to untreated plasma ( $0 \mu \mathrm{M}$ proteinase). b S. aureus strains 8325-4 (WT), 8325-4 sspABC- , 8325-4 sspBC-, 8325-4 aurRN6390 (WT) and RN6390 scp $A^{-}$were incubated for $20 \mathrm{~min}$ at $37^{\circ} \mathrm{C}$ with freshly collected human blood. After incubation, aliquots were removed, serially diluted and plated on tryptic soy agar plates. Survival was calculated as percent survival compared to the inoculum. Statistical significance of the observed differences between WT and corresponding mutant strains was determined using one-way ANOVA and a Dunnett post hoc test $\left({ }^{*} \mathrm{p}<0.05\right.$, $* * \mathrm{p}<0.01)$. pathway collectin, C1q, was not decreased (apart from a relatively small effect by ScpA, fig. 2a) but rather increased by the action of bacterial proteases. Furthermore, Aur and V8 were found to cause deposition of $\mathrm{C} 1$ from serum onto inert surfaces without the need for a specific $\mathrm{C} 1$ activator. The increased deposition of $\mathrm{Clq}$ in the presence of Aur and V8 occurred not only on blocked microtiter plates but also on the surface of $S$. epidermidis. This organism is a commensal bacterium found on the skin and in the nasal cavity of humans, is known to inhibit pathogen colonization and has been specifically shown to block biofilm formation and nasal colonization by $S$. aureus [41]. Perhaps $S$. aureus protease-induced deposition of C1q on the surface of $S$. epiderimidis could render it more vulnerable to opsonophagocytosis, resulting in its eradication, leaving the niche free for pathogen colonization. This hypothesis is further supported by the fact that the same proteases did not increase $\mathrm{Clq}$ deposi- 
tion on S. aureus itself, but rather seemed to limit the opsonization of the pathogen with $\mathrm{Clq}$ (at least Aur; fig. 5c). The role of $\mathrm{C} 1 \mathrm{q}$ in the phagocytosis of bacteria, independently of $\mathrm{C} 3 \mathrm{~b}$, has been demonstrated for several species $[42,43]$. Considering that consumption of C3 in the fluid phase due to Aur has been shown previously [18], this may remain the primary mechanism. Taking into account the vital role of $\mathrm{Clq}$ in the nonphlogistic clearance of apoptotic cells, an attractive hypothesis emerges, whereby $S$. aureus promotes the uptake of commensal species without boosting the inflammatory response.

Interestingly, ScpA, SspB and Aur were found to release biologically active $\mathrm{C} 5$ a from $\mathrm{C} 5$ present in heat-inactivated human plasma. This finding is particularly worth noting considering the increasing number of sepsis cases resulting from $S$. aureus infections and the central role of $\mathrm{C} 5 \mathrm{a}$ in the immunopathogenesis of this life-threatening syndrome [44]. It is known that neutrophils can undergo 'immune paralysis' during sepsis, an effect mediated mainly by excessive C5a levels $[45,46]$. In particular, $\mathrm{C} 5 \mathrm{a}$ rapidly induces $\mathrm{C} 5 \mathrm{a}$ receptor internalization, correlating with loss of neutrophil immune functions (chemotaxis ability and reactive oxygen species production) [47]. Increased local production of $\mathrm{C} 5 \mathrm{a}$ at infection sites could reduce the number of functional neutrophils and facilitate the dissemination of S. aureus. Notably, SspB has previously been shown to affect phagocytes, i.e. induce apoptosis-like death in human neutrophils and monocytes by selective cleavage of CD11b [48]. In addition, SspB induces the engulfment of neutrophils and monocytes by macrophages, by both the degradation of repulsion signals and induction of 'eat-me' signals on their surfaces [15]. The detrimental effects mediated by staphopain-induced C5a can be now added to this scheme.

To our surprise, the protease with the highest potential to release biologically active $\mathrm{C} 5 \mathrm{a}$ and stimulate migration of neutrophils was Aur. These observations seem at first to be in contrast with the previous study [18], where the authors reported inhibition of C5a generation by Aur based on its effect on the calcium mobilization response in U937-C5a receptor cells treated with activated serum in the presence of Aur. However, we may have identified an explanation for this discrepancy as we found that low nanomolar concentration of Aur, incubated with either purified $\mathrm{C} 5$ or heat-inactivated plasma, induced increased calcium levels in the U937-C5a receptor cells (not shown). At higher Aur concentrations, there was no increase in calcium levels (not shown), presumably due to C5a degradation.

Staphylococcal Proteases Inhibit

Complement
Another appealing aspect of $\mathrm{C} 5 \mathrm{a}$ production by bacterial proteases is the recently described cross-talk between C5a receptors $(\mathrm{C} 5 \mathrm{aR})$ and TLR receptors, which was demonstrated to be exploited by bacteria for immune evasion. P. gingivalis, which is known to generate C5a by means of its proteases, was shown to impair nitric-oxidedependent killing by macrophages utilizing subversive cross-talk between C5aR and TLR2 [49]. There is growing evidence demonstrating the prolonged survival of $S$. aureus in phagocytes $[50,51]$, but the exact mechanisms mediating this have not been clearly described. The proteases ScpA, SspB and Aur appear to be attractive candidates to study in this context.

A detailed study has previously demonstrated that Aur acts on complement component $\mathrm{C} 3$ and blocks phagocytosis by converting $\mathrm{C} 3$ to active $\mathrm{C} 3 \mathrm{~b}$, which then becomes vulnerable to degradation by host complement inhibitor factors $\mathrm{H}$ and I [18]. Importantly, we were able to confirm these previously published findings (not shown). C3b release due to cleavage of $\mathrm{C} 3$ by Aur is accompanied by $\mathrm{C} 3 \mathrm{a}$ production, which is then further processed to smaller fragments in the presence of Aur and serum, and therefore does not induce neutrophil activation [18]. This seems to be a protective strategy of the bacterium since $\mathrm{C} 3 \mathrm{a}$, in contrast to $\mathrm{C} 5 \mathrm{a}$, has direct antibacterial activity [52]. Interestingly, we found that $\mathrm{SspB}$ does not cleave intact $\mathrm{C} 3$, but it does degrade $\mathrm{C} 3 \mathrm{~b}$, both deposited on a plate and in fluid phase (data not shown). One can speculate that there may be a cooperative action between Aur and $\mathrm{SspB}$, whereby Aur converts $\mathrm{C} 3$ to $\mathrm{C} 3 \mathrm{~b}$, which is then degraded further by SspB.

To address the overall effect of $S$. aureus proteases on survival of this bacterium, we used mutants depleted in protease genes. Due to the fact that proteases are mainly expressed during the postexponential phase [9], we used overnight bacterial cultures, since under such conditions there was the highest detectable proteolytic activity in the media of laboratory strains. Most of the analyzed mutant strains lacking proteases, which were cultured in such conditions and suspended in media from overnight cultures, showed significantly reduced survival compared to WT. However, caution is required in the interpretation of these results. Staphylococcal proteolytic enzymes (ScpA, SspB, V8 and Aur) are expressed as zymogens and must be activated in an interdependent, cascade-like manner. Aur is required for proV8 activation and releases the mature active form of $\mathrm{V} 8$, which in turn activates proSspB $[9,53]$. Aur appears to be activated via autocatalysis [54], whereas it is still unclear how proScpA (located outside this activation cascade) is cleaved, although it is also

J Innate Immun 2014;6:31-46 DOI: $10.1159 / 000351458$ 
thought to be via an autocatalytic process [55]. In light of these data, one would expect that aur deletion results in lack of active Aur, V8 and SspB, and therefore more pronounced effects should be expected for this mutant. However, some activation of proV8 and proSspB has been observed in aur-negative mutant strains [9], suggesting the existence of backup activation mechanisms. A whole blood killing assay is perhaps not sensitive enough to clearly show the differences between different mutants, yet slightly larger effects on bacterial survival were observed (with higher significance) for the aur-deficient strain, compared to $s p B C^{-}$and $s s p A B C^{-}$knockouts. It is worth noting that we prove a crucial role in survival for SspB using the $\operatorname{ssp} B C^{-}$knockout, whereas we cannot clearly say, based on these results, if Aur and V8 play a role in bacterial survival, or if the effects observed with ssp $A B C^{-}$and $a u r^{-}$knockouts are due to a lack of mature SspB. In contrast, we did not observe an effect on survival for an $S c p A^{-}$mutant.

The increased survival of the WT strain expressing all $S$. aureus proteases in whole blood might indicate its diminished clearance by opsonophagocytosis and neutrophil activation; processes linked to, and promoted by, complement activation. In keeping with our results, a protease-null strain lacking all 10 exoproteases exhibited limited growth in serum and largely reduced survival in human blood [56]. However, due to the numerous actions of proteases on other components of host immunity, such as phagocytes or the coagulation system, we are not able to pinpoint exactly what portion of pathogen survivability can be attributed to the effect of proteases on complement. It is hard to design a conclusive experiment since $S$. aureus cannot be killed by complement without the contribution of cellular components.

Since the expression and activation of these different proteases seems to be correlated and interdependent, we can suppose that they act in concert, and therefore exert an enhanced or even synergistic effect on complement, implying the requirement of much lower concentrations of individual proteases than those used here in in vitro experiments. In terms of relative concentrations of individual enzymes, it seems that staphopains $A$ and $B$ are the most intensively secreted of all the staphylococcal proteases [57], allowing for speculation that their influence will be dominant.

The overall effect of the proteases seems to be in shutting down complement. However, not only inhibition but also activation of complement appears to be the purpose of these proteases, suggesting that $S$. aureus can in fact modulate complement depending on the conditions.
Similar activating effects on complement, in combination with the general inhibition of its cascades, were previously identified for proteases from other human pathogens, including $P$. gingivalis, $P$. intermedia and $T$. forsythia, all of which are involved in periodontal disease [6-8]. The common intersecting points with these strains is the release of anaphylatoxin $\mathrm{C} 5 \mathrm{a}$ and the increased $\mathrm{C} 1 \mathrm{q}$ deposition on inert surfaces in the absence of specific complement activators. Perhaps these findings indicate the existence of a more general mechanism of complement corruption utilized by human pathogens, although more studies are necessary to confirm this hypothesis. It is clear that proteolytic enzymes play an important role in $S$. aureus immune evasion. Our work presents certain key findings in this regard, but still leaves space for a more detailed characterization of the effects of individual proteases and their specific functions.

\section{Acknowledgments}

This work was supported by the Swedish Medical Research Council (K2012-66X-14928-09-5), Foundations of Torsten Söderberg, Österlund, Kock, King Gustav V's 80th Anniversary, Knut and Alice Wallenberg, Inga-Britt and Arne Lundberg, research grants from the Foundation of the National Board of Health and Welfare and the Skåne University Hospital (to A.M.B.), and grants from the National Institutes of Health [grant DE 09761, USA (J.P.) and AI090350 (L.N.S.)], the National Science Center (2011/01/B/ NZ6/00268, Kraków, Poland; to J.P.), IUVENTUS Plus from MNiSW (0221/IP1/2011/71 Warsaw, Poland; to T.K.), the Novo Nordisk Research Foundation and Sven Andersen Research Foundation (to P.G.). The Faculty of Biochemistry, Biophysics and Biotechnology of the Jagiellonian University is a beneficiary of structural funds from the European Union (POIG.02.01.00-12-064/08).

\section{Disclosure Statement}

All authors report no conflicts of interest related to the study.

References

1 Kluytmans J, van Belkum A, Verbrugh H: Nasal carriage of Staphylococcus aureus: epidemiology, underlying mechanisms, and associated risks. Clin Microbiol Rev 1997;10:505520.

2 Lowy FD: Staphylococcus aureus infections. N Engl J Med 1998;339:520-532.

3 Foster TJ: Colonization and infection of the human host by staphylococci: adhesion, survival and immune evasion. Vet Dermatol 2009;20:456-470.

4 Lambris JD, Ricklin D, Geisbrecht BV: Complement evasion by human pathogens. Nat Rev Microbiol 2008;6:132-142.
Jusko/Potempa/Kantyka/Bielecka/Miller/ Kalinska/Dubin/Garred/Shaw/Blom 
5 Serruto D, Rappuoli R, Scarselli M, Gros P, van Strijp JA: Molecular mechanisms of complement evasion: learning from staphylococci and meningococci. Nat Rev Microbiol 2010;8: 393-399.

-6 Jusko M, Potempa J, Karim AY, Ksiazek M, Riesbeck K, Garred P, Eick S, Blom AM: A metalloproteinase karilysin present in the majority of Tannerella forsythia isolates inhibits all pathways of the complement system. J Immunol 2012;188:2338-2349.

7 Popadiak K, Potempa J, Riesbeck K, Blom AM: Biphasic effect of gingipains from Porphyromonas gingivalis on the human complement system. J Immunol 2007;178:72427250.

8 Potempa M, Potempa J, Kantyka T, Nguyen KA, Wawrzonek K, Manandhar SP, Popadiak K, Riesbeck K, Eick S, Blom AM: Interpain A, a cysteine proteinase from Prevotella intermedia, inhibits complement by degrading complement factor C3. PLoS Pathog 2009; 5:e1000316.

-9 Shaw L, Golonka E, Potempa J, Foster SJ: The role and regulation of the extracellular proteases of Staphylococcus aureus. Microbiology 2004;150:217-228.

10 Potempa J, Pike RN: Corruption of innate immunity by bacterial proteases. J Innate Immun 2009;1:70-87.

11 Potempa J, Watorek W, Travis J: The inactivation of human plasma alpha 1-proteinase inhibitor by proteinases from Staphylococcus aureus. J Biol Chem 1986;261:1433014334.

12 Potempa J, Fedak D, Dubin A, Mast A, Travis J: Proteolytic inactivation of alpha-1-antichymotrypsin. Sites of cleavage and generation of chemotactic activity. J Biol Chem 1991;266:21482-21487.

13 Ohbayashi T, Irie A, Murakami Y, Nowak M, Potempa J, Nishimura Y, Shinohara M, Imamura T: Degradation of fibrinogen and collagen by staphopains, cysteine proteases released from Staphylococcus aureus. Microbiology 2011;157:786-792.

14 Potempa J, Dubin A, Korzus G, Travis J: Degradation of elastin by a cysteine proteinase from Staphylococcus aureus. J Biol Chem 1988;263:2664-2667.

15 Smagur J, Guzik K, Bzowska M, Kuzak M, Zarebski M, Kantyka T, Walski M, Gajkowska B, Potempa J: Staphylococcal cysteine protease staphopain B (SspB) induces rapid engulfment of human neutrophils and monocytes by macrophages. Biol Chem 2009;390:361371.

16 Prokesova L, Potuznikova B, Potempa J, Zikan J, Radl J, Hachova L, Baran K, Porwit-Bobr Z, John C: Cleavage of human immunoglobulins by serine proteinase from Staphylococcus aureus. Immunol Lett 1992;31: 259-265.
17 Sieprawska-Lupa M, Mydel P, Krawczyk K, Wojcik K, Puklo M, Lupa B, Suder P, Silberring J, Reed M, Pohl J, Shafer W, McAleese F, Foster T, Travis J, Potempa J: Degradation of human antimicrobial peptide LL-37 by Staphylococcus aureus-derived proteinases. Antimicrob Agents Chemother 2004;48:46734679.

18 Laarman AJ, Ruyken M, Malone CL, van Strijp JA, Horswill AR, Rooijakkers SH: Staphylococcus aureus metalloprotease aureolysin cleaves complement $\mathrm{C} 3$ to mediate immune evasion. J Immunol 2011;186:6445-6453.

19 Wegrzynowicz Z, Heczko PB, Drapeau GR, Jeljaszewicz J, Pulverer G: Prothrombin activation by a metalloprotease from Staphylococcus aureus. J Clin Microbiol 1980;12:138139.

20 Imamura T, Tanase S, Szmyd G, Kozik A, Travis J, Potempa J: Induction of vascular leakage through release of bradykinin and a novel kinin by cysteine proteinases from Staphylococcus aureus. J Exp Med 2005;201:16691676.

21 Molla A, Yamamoto T, Akaike T, Miyoshi S, Maeda H: Activation of Hageman factor and prekallikrein and generation of kinin by various microbial proteinases. J Biol Chem 1989; 264:10589-10594.

22 Arvidson S, Holme T, Lindholm B: Studies on extracellular proteolytic enzymes from Staphylococcus aureus. I. Purification and characterization of one neutral and one alkaline protease. Biochim Biophys Acta 1973;302:135148.

23 Drapeau GR: Protease from Staphyloccus aureus. Methods Enzymol 1976;45:469-475.

24 Popowicz GM, Dubin G, Stec-Niemczyk J, Czarny A, Dubin A, Potempa J, Holak TA: Functional and structural characterization of Spl proteases from Staphylococcus aureus. J Mol Biol 2006;358:270-279.

25 Munthe-Fog L, Hummelshoj T, Hansen BE, Koch C, Madsen HO, Skjodt K, Garred P: The impact of FCN2 polymorphisms and haplotypes on the Ficolin-2 serum levels. Scand J Immunol 2007;65:383-392.

26 Munthe-Fog L, Hummelshoj T, Ma YJ, Hansen BE, Koch C, Madsen HO, Skjodt K, Garred P: Characterization of a polymorphism in the coding sequence of FCN3 resulting in a Ficolin-3 (Hakata antigen) deficiency state. Mol Immunol 2008;45:2660-2666.

27 Hein E, Honore C, Skjoedt MO, Munthe-Fog L, Hummelshoj T, Garred P: Functional analysis of Ficolin-3 mediated complement activation. PLoS One 2010;5:e15443.

28 Amara U, Flierl MA, Rittirsch D, Klos A, Chen $\mathrm{H}$, Acker B, Bruckner UB, Nilsson B, Gebhard F, Lambris JD, Huber-Lang M: Molecular intercommunication between the complement and coagulation systems. J Immunol 2010;185:5628-5636.
29 Mollnes TE, Brekke OL, Fung M, Fure H, Christiansen D, Bergseth G, Videm V, Lappegard KT, Kohl J, Lambris JD: Essential role of the $\mathrm{C} 5 \mathrm{a}$ receptor in $\mathrm{E}$ coli-induced oxidative burst and phagocytosis revealed by a novel lepirudin-based human whole blood model of inflammation. Blood 2002;100: 1869-1877.

30 Karlsson A, Arvidson S: Variation in extracellular protease production among clinical isolates of Staphylococcus aureus due to different levels of expression of the protease repressor SarA. Infect Immun 2002;70:4239-4246.

31 Oogai Y, Matsuo M, Hashimoto M, Kato F, Sugai M, Komatsuzawa H: Expression of virulence factors by Staphylococcus aureus grown in serum. Appl Environ Microbiol 2011;77: 8097-8105.

32 Abdelnour A, Arvidson S, Bremell T, Ryden C, Tarkowski A: The accessory gene regulator (agr) controls Staphylococcus aureus virulence in a murine arthritis model. Infect Immun 1993;61:3879-3885.

33 Cheung AL, Eberhardt KJ, Chung E, Yeaman MR, Sullam PM, Ramos M, Bayer AS: Diminished virulence of a sar-/agr- mutant of Staphylococcus aureus in the rabbit model of endocarditis. J Clin Invest 1994;94:1815-1822.

-34 Chan PF, Foster SJ: Role of SarA in virulence determinant production and environmental signal transduction in Staphylococcus aureus. J Bacteriol 1998;180:6232-6241.

- 35 McGavin MJ, Zahradka C, Rice K, Scott JE: Modification of the Staphylococcus aureus fibronectin binding phenotype by V8 protease. Infect Immun 1997;65:2621-2628.

36 McAleese FM, Walsh EJ, Sieprawska M, Potempa J, Foster TJ: Loss of clumping factor B fibrinogen binding activity by Staphylococcus aureus involves cessation of transcription, shedding and cleavage by metalloprotease. J Biol Chem 2001;276:29969-29978.

37 Timar KK, Dallos A, Kiss M, Husz S, Bos JD, Asghar SS: Expression of terminal complement components by human keratinocytes. Mol Immunol 2007;44:2578-2586.

38 Dovezenski N, Billetta R, Gigli I: Expression and localization of proteins of the complement system in human skin. J Clin Invest 1992;90:2000-2012.

- 39 Neth O, Jack DL, Dodds AW, Holzel H, Klein NJ, Turner MW: Mannose-binding lectin binds to a range of clinically relevant microorganisms and promotes complement deposition. Infect Immun 2000;68:688-693.

40 Lynch NJ, Roscher S, Hartung T, Morath S, Matsushita M, Maennel DN, Kuraya M, Fujita T, Schwaeble WJ: L-ficolin specifically binds to lipoteichoic acid, a cell wall constituent of Gram-positive bacteria, and activates the lectin pathway of complement. J Immunol 2004;172:1198-1202.

-41 Iwase T, Uehara Y, Shinji H, Tajima A, Seo H, Takada K, Agata T, Mizunoe Y: Staphylococcus epidermidis Esp inhibits Staphylococcus aureus biofilm formation and nasal colonization. Nature 2010;465:346-349.
Staphylococcal Proteases Inhibit Complement 
42 Yuste J, Ali S, Sriskandan S, Hyams C, Botto M, Brown JS: Roles of the alternative complement pathway and $\mathrm{Clq}$ during innate immunity to Streptococcus pyogenes. J Immunol 2006;176:6112-6120.

43 Alvarez-Dominguez C, Carrasco-Marin E, Leyva-Cobian F: Role of complement component C1q in phagocytosis of Listeria monocytogenes by murine macrophage-like cell lines. Infect Immun 1993;61:3664-3672.

44 Ward PA: The harmful role of C5a on innate immunity in sepsis. J Innate Immun 2010;2: 439-445.

-45 Solomkin JS, Jenkins MK, Nelson RD, Chenoweth D, Simmons RL: Neutrophil dysfunction in sepsis. II. Evidence for the role of complement activation products in cellular deactivation. Surgery 1981;90:319-327.

46 Riedemann NC, Guo RF, Bernacki KD, Reuben JS, Laudes IJ, Neff TA, Gao H, Speyer C, Sarma VJ, Zetoune FS, Ward PA: Regulation by C5a of neutrophil activation during sepsis. Immunity 2003;19:193-202.

-47 Guo RF, Riedemann NC, Bernacki KD, Sarma VJ, Laudes IJ, Reuben JS, Younkin EM, Neff TA, Paulauskis JD, Zetoune FS, Ward PA: Neutrophil C5a receptor and the outcome in a rat model of sepsis. FASEB J 2003;17:18891891.
48 Smagur J, Guzik K, Magiera L, Bzowska M, Gruca M, Thogersen IB, Enghild JJ, Potempa J: A new pathway of staphylococcal pathogenesis: apoptosis-like death induced by staphopain B in human neutrophils and monocytes. J Innate Immun 2009; 1:98-108.

49 Wang M, Krauss JL, Domon H, Hosur KB, Liang S, Magotti P, Triantafilou M, Triantafilou K, Lambris JD, Hajishengallis G: Microbial hijacking of complement-toll-like receptor crosstalk. Sci Signal 2010;3:ra11.

50 Voyich JM, Braughton KR, Sturdevant DE, Whitney AR, Said-Salim B, Porcella SF, Long RD, Dorward DW, Gardner DJ, Kreiswirth BN, Musser JM, DeLeo FR: Insights into mechanisms used by Staphylococcus aureus to avoid destruction by human neutrophils. J Immunol 2005;175:3907-3919.

51 Kubica M, Guzik K, Koziel J, Zarebski M, Richter W, Gajkowska B, Golda A, MaciagGudowska A, Brix K, Shaw L, Foster T, Potempa J: A potential new pathway for Staphylococcus aureus dissemination: the silent survival of S. aureus phagocytosed by human monocyte-derived macrophages. PLoS One 2008;3:e1409.

52 Pasupuleti M, Walse B, Nordahl EA, Morgelin M, Malmsten M, Schmidtchen A: Preservation of antimicrobial properties of complement peptide $\mathrm{C} 3 \mathrm{a}$, from invertebrates to humans. J Biol Chem 2007;282:2520-2528.

53 Drapeau GR: Role of metalloprotease in activation of the precursor of staphylococcal protease. J Bacteriol 1978;136:607-613.
54 Nickerson NN, Joag V, McGavin MJ: Rapid autocatalytic activation of the M4 metalloprotease aureolysin is controlled by a conserved $\mathrm{N}$-terminal fungalysin-thermolysin-propeptide domain. Mol Microbiol 2008;69:15301543.

55 Nickerson N, Ip J, Passos DT, McGavin MJ: Comparison of staphopain A (ScpA) and B $(\mathrm{Sspb})$ precursor activation mechanisms reveals unique secretion kinetics of proSspB (staphopain b), and a different interaction with its cognate staphostatin, SspC. Mol Microbiol 2010;75:161-177.

56 Kolar SL, Antonio Ibarra J, Rivera FE, Mootz JM, Davenport JE, Stevens SM, Horswill AR, Shaw LN: Extracellular proteases are key mediators of Staphylococcus aureus virulence via the global modulation of virulence-determinant stability. Microbiologyopen 2013;2: 18-34.

57 Jones RC, Deck J, Edmondson RD, Hart ME: Relative quantitative comparisons of the extracellular protein profiles of Staphylococcus aureus UAMS-1 and its sarA, agr, and sarA agr regulatory mutants using one-dimensional polyacrylamide gel electrophoresis and nanocapillary liquid chromatography coupled with tandem mass spectrometry. J Bacteriol 2008; 190:5265-5278. 